\title{
Strategi Pengembangan Program Kawasan Rumah Pangan Lestari (KRPL) pada Kelompok Wanita Tani Karya Harum di Desa Karang Sidemen, Lombok Tengah
}

\author{
BAIQ RIA ASKINA, I WAYAN WINDIA, \\ I GUSTI AYU AGUNG LIES ANGGRENI
}

\author{
Program Studi Agribisnis Fakultas Pertanian Universitas Udayana \\ J1. PB. Sudirman Denpasar 80232 \\ Email: askinagina@gmail.com \\ wayanwindia@ymail.com
}

\begin{abstract}
Region Development Strategy for Sustainable Food Houses Program (KRPL) on Women Farmers Group Karya Harum Village of Karang Sidemen Central Lombok Regency
\end{abstract}

KRPL program is the concept of optimizing the use of yard area with a variety of crops, livestock and fish in one area.The research objective was to determine the internal and external factors and determine the development strategy KRPL program in the village of Karang Sidemen.The results of the analysis of internal factors Karya Harum group: a) the power (the availability of nurseries and mastery of technology is the most influential factor) b) weakness (the education background of KWT management is still a major factor of group weakness). External factors: a) the opportunities (the presence of a certain partner is an important factor) b) threats (the weather conditions are a threat within KRPL program development). Based on SWOT analysis, there are development strategies: a) SO strategy that is revitalizing the village seedlings (KBD) and strategy to maintain the partners, b) WO strategy is the strategy of increasing the quantity of cultivation of plants and training strategy of product development of the product of the yard, c)ST strategy namely water and hydroponics harvesting technology extension strategies to the group, d) WT strategy is stimulant strategy. Priority of strategy can be done by reviving the KBD and maintaining partners.

Keywords: strategy, program KRPL, SWOT analysis

\section{Pendahuluan}

\subsection{Latar Belakang}

Tantangan utama dalam penyedia pangan dihadapkan pada ketersediaan sumber daya lahan yang semakin langka (lack of resources), baik luas maupun kualitas serta konflik kepentingan (conflict of interest). Kelangkaan tersebut disebabkan semakin meningkatnya penggunaan lahan pertanian ke non pertanian 
yang bersifat permanen (irrevisible) dan multiplikasi (BPTP NTB, 2012). Kementrian Pertanian melalui Badan Penelitian dan Pengembangan Pertanian mengembangkan suatu konsep yang disebut Model Kawasan Rumah Pangan Lestari (MKRPL). Program Kawasan Rumah Pangan Lestari (KRPL) ini merupakan terobosan dalam menghadapi perubahan iklim melalui pemanfaatan pekarangan dalam mendukung ketersediaan serta diversifikasi pangan (BPTP NTB, 2012). Menurut Ashari, Saptana, dan Tri (2012) menjelaskan bahwa program pemanfaatan lahan pekarangan baru secara eksplisit dimasukkan menjadi bagian dari proyek pengembangan diversifikasi dan gizi (FGD).

Implementasi KRPL di NTB sejak 2011 hingga 2013 telah mencapai 24 lokasi yang tersebar di $10 \mathrm{Kab} /$ Kota dengan bentuk dan tampilan yang bervariasi antar kawasan. Hingga saat ini jumlah anggota rumah tangga peserta M-KRPL di NTB terus bertambah (BPTP NTB, 2014). Jumlah anggota KRPL tahun 2011-2012 bertambah dari $229 \mathrm{KK}$ menjadi $291 \mathrm{KK}$ atau meningkat sebesar 27,07\% (BPTP NTB, 2013). Kelompok Wanita Tani (KWT) Karya Harum di Desa Karang Sidemen, Kecamatan Batukliang Utara, Kabupaten Lombok Tengah adalah kelompok KRPL binaan pertama Balai Pengkajian Teknologi Pertanian (BPTP) NTB yang dimulai akhir Oktober 2011 (BPTP NTB, 2013).

Melihat berbagai kemungkinan akan ketersediaan bahan pangan yang semakin berkurang dan untuk menekan pengeluaran ketika harga kebutuhan melambung tinggi. Harapan ke depan bahwa KWT tersebut, dapat menentukan langkah manajemen secara bijak dalam mengambil keputusan terhadap kemungkinan kondisi tersebut. Menurut Siagian (2004), manajemen strategi mengkombinasikan pola pikir strategi dengan proses manajemen.

Berdasarkan kondisi tersebut, perlu diketahui faktor internal dan faktor eksternal KWT Karya Harum serta mengetahui strategi pengembangan program KRPL berdasarkan strategi alternatif. Hal ini sebagai bahan acuan dan pembelajaran bagi KWT lain dalam pengembangan dan pelaksanaan program M-KRPL sehingga bisa berkembang dan sukses baik untuk saat ini maupun untuk masa yang akan datang.

\subsection{Tujuan}

Tujuan penelitian ini adalah mengetahui faktor internal dan faktor eskternal program KRPL pada KWT Karya Harum serta mengetahui strategi pengembangan program KRPL berdasarkan strategi alternatif.

\section{Metode Penelitian}

\subsection{Lokasi dan Waktu Penelitian}

Penelitian ini berlangsung selama lima bulan yaitu bulan Oktober tahun 2016 sampai bulan Februari 2017 mulai dari persiapan hingga penyusunan laporan. Lokasi penelitian dipilih secara purposive di Desa Karang Sidemen, Kecamatan Batukliang Utara, Kabupaten Lombok Tengah. Dasar pertimbangannya : (1)KWT Karya Harum 
merupakan binaan pertama BPTP dalam pelaksanaan program KRPL;(2)KWT Karya Harum masih tetap bertahan sampai sekarang dan(3)KWT Karya Harum merupakan kelompok yang sudah lebih maju dan berhasil dibandingkan KWT lain dalam melaksanakan program KRPL.

\subsection{Jenis dan Sumber Data}

Jenis data penelitian ini adalah kualitatif dan kuantitatif. Sumber data penelitian ini adalah data primer dan data sekunder.

\subsection{Metode Pengumpulan Data}

Data faktor lingkungan internal dan faktor lingkungan eksternal KWT Karya Harum di Desa Karang Sidemen dikumpulkan melalui obeservasi, melakukan wawancara langsung dengan responden dengan bantuan daftar pertanyaan (kuesioner),wawancara mendalam, dan studi dokumentasi.

\subsection{Populasi dan Responden}

Populasi penelitian ini adalah semua anggota KWT Karya Harum berjumlah 30. Sampel (responden) penelitian ini adalah anggota KWT Karya Harum yang masih aktif berjumlah 25 orang sedangkan lima orang tidak aktif, tidak dijadikan responden. Informan kunci yang juga dijadikan responden yaitu petugas BPTP yang menangani proyek program KRPL sebanyak lima orang. Pengambilan sampel (responden) penelitian ini dilakukan dengan secara sensus.

\subsection{Variabel dan Analisis Data}

Variabel-variabel yang dianalisis dalam penelitian ini adalah:(1) Kekuatan (strength); (2) Kelemahan (weaknesses); (3) Peluang (opportunities) dan (4) Ancaman (threats). Variabel-variabel dalam penelititan ini akan dianalisis dengan metode deskriptif dibantu dengan analisis SWOT termasuk penggunaan matriks IFAS-EFAS, matriks internal-eksternal (I-E), matriks SWOT, dan diagram analisis SWOT.

\section{Hasil dan Pembahasan}

\subsection{Identifikasi Faktor Internal dan Faktor Eksternal KWT Karya Harum \\ 3.1.1 Identifikasi faktor internal}

Faktor lingkungan internal menurut Reksodipardjo (1992) adalah faktor yang berada di dalam KWT Karya Harum di Desa Karang Sidemen itu sendiri dalam pelaksanaan program KRPL. Melaui indentifikasi lingkungan internal maka dapat diketahui kekuatan dan kelemahan yang ada pada KWT Karya Harum.Adapun faktor lingkungan internal KWT Karya Harum di Desa Karang Sidemen adalah sebagai berikut.

1. Faktor internal kekuatan yaitu: (a) ketersediaan kebun bibit, (b) penguasaan teknologi cukup baik, (c) adanya rapat rutin anggota setiap bulan sekali, 
(d) adanya industri pengolahan hasil, (e) sudah mampu memenuhi kebutuhan konsumsi keluarga, dan (f) mampu memasarkan hasil ke daerah lain.

2. Faktor internal kelemahan yaitu: (a) pendidikan pengurus KWT, (b) menurunnya minat anggota, (c) akses jalan masih jelek, dan (d) belum bisa memenuhi pasar terhadap hasil.

\subsubsection{Identifikasi faktor eksternal}

Faktor lingkungan eksternal adalah faktor yang berada diluar KWT Karya Harum di Desa Karang Sidemen yang dapat mempengaruhi kelompok tersebut. Fakor tersebut dapat berupa peluang dan ancaman. Adapun faktor lingkungan eksternal KWT Karya Harum di Desa Karang Sidemen adalah sebagai berikut.

1. Faktor eksternal peluang yaitu: (a) tersedianya pasar tradisional, (b) adanya mitra kerja yang jelas, (c) kondisi sosial dan ekonomi stabil, dan (d) adanya kebijakan pemanfaatan lahan pekarangan.

2. Faktor eksternal ancaman yaitu: (a) kondisi cuaca tidak menentu, (b) adanya kompetitor dari kelompok lain, dan (c) masih ada masyarakat yang memilih membeli sayur daripada menanam sayur.

\subsection{Strategi Pengembangan Program KRPL pada KWT Karya Harum}

\subsubsection{Hasil evaluasi faktor strategi internal}

Berikut adalah hasil penghitungan matriks IFAS yang dapat dilihat pada tabel dibawah ini.

Tabel 1.

Penghitungan Matriks Evaluasi Faktor Internal Strategi Pengembangan Program KRPL pada KWT Karya Harum di Desa Karang Sidemen

\begin{tabular}{llccc}
\hline \multicolumn{2}{c}{ Faktor Internal } & & & \\
\hline No & Kekuatan & Bobot & Rating & Skor \\
\hline & Ketersediaan kebun bibit & 0,11 & 3 & 0,34 \\
2 & Penguasaan teknologi cukup baik & 0,11 & 3 & 0,33 \\
3 & Adanya rapat rutin setian bulan sekali & & 3 & 0,23 \\
4 & Adanya industri pengolahan hasil & 0,08 & 3 & 0,24 \\
5 & Sudah mampu memenuhi kebutuhan konsumsi keluarga & 0,07 & 3 & 0,21 \\
6 & Mampu menjual hasil ke daerah lain & 0,05 & 2 & 0,1 \\
\hline & Kelemahan & & & \\
\hline 1 & Pendidikan pengurus KWT & 0,18 & 3 & 0,54 \\
2 & Menurunnya minat anggota & 0,12 & 3 & 0,36 \\
3 & Akses jalan masih jelek & 0,11 & 3 & 0,32 \\
4 & Belum bisa memenuhi permintaan pasar luar terhadap hasil & 0,09 & 3 & 0,28 \\
\hline & $\quad$ Total Kekuatan + Kelemahan & 1 & 29 & 2,95 \\
\hline Sumber $:$ Pengolahan data primer 2017 & & &
\end{tabular}


Berdasarkan tabel 1 terlihat bahwa faktor-faktor strategi internal memiliki nilai yang bervariasi. Faktor kekuatan terpenting pertama adalah ketersediaan kebun bibit dan penguasaan teknologi dengan perolehan nilai skor sebesar 0,34 dan 0,33. Masing-masing faktor tersebut memiliki nilai bobot sebersar 0,11 dan nilai rating 3 yang berarti kedua faktor tersebut kuat.

Adapun kelemahan utama dalam pengembangan program KRPL pada KWT Karya Harum adalah pendidikan pengurus KWT dengan nilai skor sebesar 0,54 dan nilai bobot 0,18 dan disusul dengan menurunnya minat anggota KWT dengan nilai skor sebesar 0,36 dan nilai bobot 0,12. Melihat total skor faktor strategi internal sebesar 2,95 termasuk ke dalam kategori kuat, karena total skor yang berada di bawah 2,5 menandakan faktor strategi internal yang lemah (David, 2000). Hal tersebut menunjukkan, KWT telah mampu memanfaatkan kekuatan untuk mengatasi kelemahan.

\subsubsection{Hasil evaluasi faktor strategi eksternal}

Berikut adalah hasil penghitungan matriks EFAS yang dapat dilihat dibawah ini.

Tabel 2.

Penghitungan Matriks Evaluasi Faktor Eksternal Strategi Pengembangan Program KRPL pada KWT Karya Harum di Desa Karang Sidemen

\begin{tabular}{|c|c|c|c|c|}
\hline \multicolumn{5}{|c|}{ Faktor Eksternal } \\
\hline No & Peluang & Bobot & Rating & Skor \\
\hline 1 & Tersdianya pasar tradisioanl & 0,13 & 3 & 0,4 \\
\hline 2 & Adanya mitra kerja yang jelas & 0,14 & 3 & 0,41 \\
\hline 3 & Kondisi sosial dan ekonomi stabil & 0,11 & 3 & 0,33 \\
\hline 4 & Adanya kebijakan pemanfaatan lahan pekarangan & 0,12 & 3 & 0,36 \\
\hline \multicolumn{5}{|c|}{ Ancaman } \\
\hline 1 & Kondisi cuaca tidak menentu & 0,18 & 3 & 0,53 \\
\hline 2 & Adanya kompetitor dari kelompok lain & 0,15 & 2 & 0,29 \\
\hline 3 & Masih ada masyrakat yang memilih membeli daripada menaman sayur & 0,18 & 2 & 0,35 \\
\hline \multicolumn{2}{|r|}{ Total Peluang + Ancaman } & 1 & 19 & 2,68 \\
\hline
\end{tabular}

Berdasarkan tabel 2 terlihat bahwa faktor eksternal yang terdiri dari faktor peluang dan faktor ancaman memperoleh nilai yang bervariasi. Faktor peluang yang terpenting adalah adanya mitra kerja yang jelas dengan perolehan nilai skor 0,41 , nilai bobot sebesar 0,14 dan rating 3 yang berarti kuat.

Ancaman yang paling kuat adalah adanya kondisi cuaca yang tidak menentu dengan perolehan skor sebanyak 0,53 dan nilai bobot sebanyak 0,18. Adanya kondisi cuaca yang tidak menentu ini tentu saja menjadi ancaman dalam pelaksanaan program KRPL terutama dalam pemanfaatan lahan pekarangan. KWT tersebut harus 
berusaha mencari solusi untuk menghadapi ancaman tersebut dengan memanfaatkan berbagai teknologi yang ada.

Total skor faktor strategi eksternal berdasarkan perhitungan matriks EFAS adalah sebesar 2,68 yang berarti termasuk ke dalam kategori cukup kuat, karena total skor yang berada di atas rata-rata 2,5 termasuk cukup kuat (David, 2000). Hal tersebut menunjukkan bahwa KWT telah mampu memanfaatkan peluang dan mengatasi ancaman yang ada.

\subsubsection{Analisis matriks internal-eksternal (I-E)}

Mengetahui arah dan posisi dari pengembangan program KRPL pada KWT Karya Harum, maka dapat dilakukan dengan menggunakan analisis matriks InternalEksternal (I-E). Analisis matriks I-E menggunakan dua dimensi yaitu hasil perhitungan matriks IFAS (IFE) dan hasil perhitungan matriks EFAS (EFE). Adapun hasil perhitungan matriks I-E terhadap pengembangan program KRPL pada KWT Karya Harum dapat dilihat pada tabel 3.

Tabel 3.

Penghitungan Matriks Internal-Eksternal (I-E) terhadap Pengembangan Program KRPL pada KWT Karya Harum di Desa Karang Sidemen

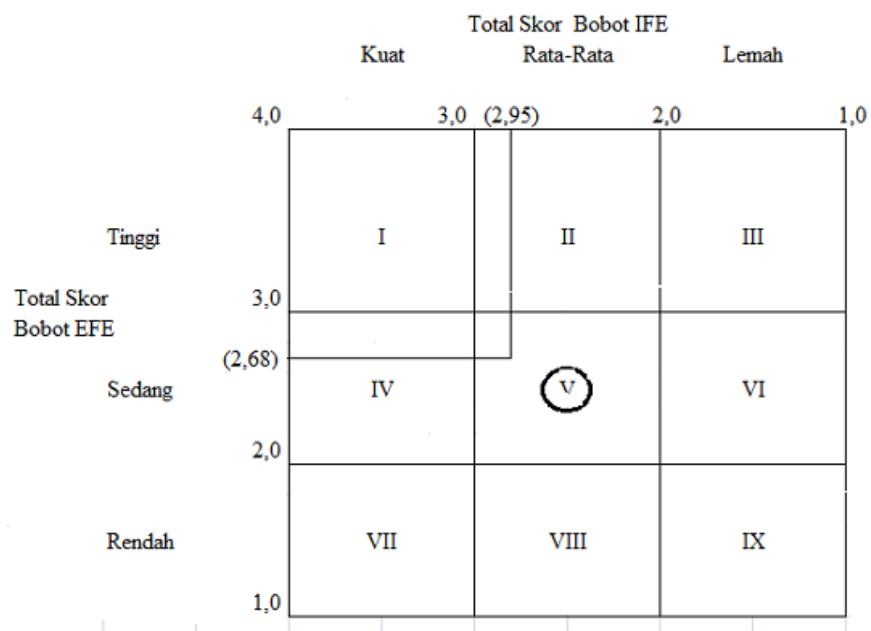

Berdasarkan tabel 3 pemetaan terhadap masing-masing total skor, baik dari faktor internal dan faktor eksternal menggambarkan posisi program KRPL pada KWT Karya Harum, saat ini berada pada posisi sedang yaitu sel V dalam matriks IE. Strategi yang dapat dijalankan adalah strategi pertahankan dan pelihara; penetrasi pasar, pengembangan produk merupakan dua strategi yang terbanyak dilakukan untuk tipe-tipe divisi ini (David, 2000).

\subsubsection{Analisis matriks SWOT}

Analisis SWOT merupakan strategi alternatif pengembangan program KRPL pada KWT Karya Harum di Desa Karang Sidemen. Menurut Rangkuti 
(2016),matriks SWOT menghasilkan empat sel kemungkinan alternatif pengembangan program KRPL dengan potensi dan kondisi lingkungan internal dan lingkungan eksternal yang dimiliki KWT Karya Harum di Desa Karang Sidemen.Matriks analisis SWOT KWT Karya Harum di Desa Karang Sidemen dapat dilihat pada tabel 4 .

Tabel 4.

Penyusunan Alternatif Strategi Menggunakan Matriks SWOT

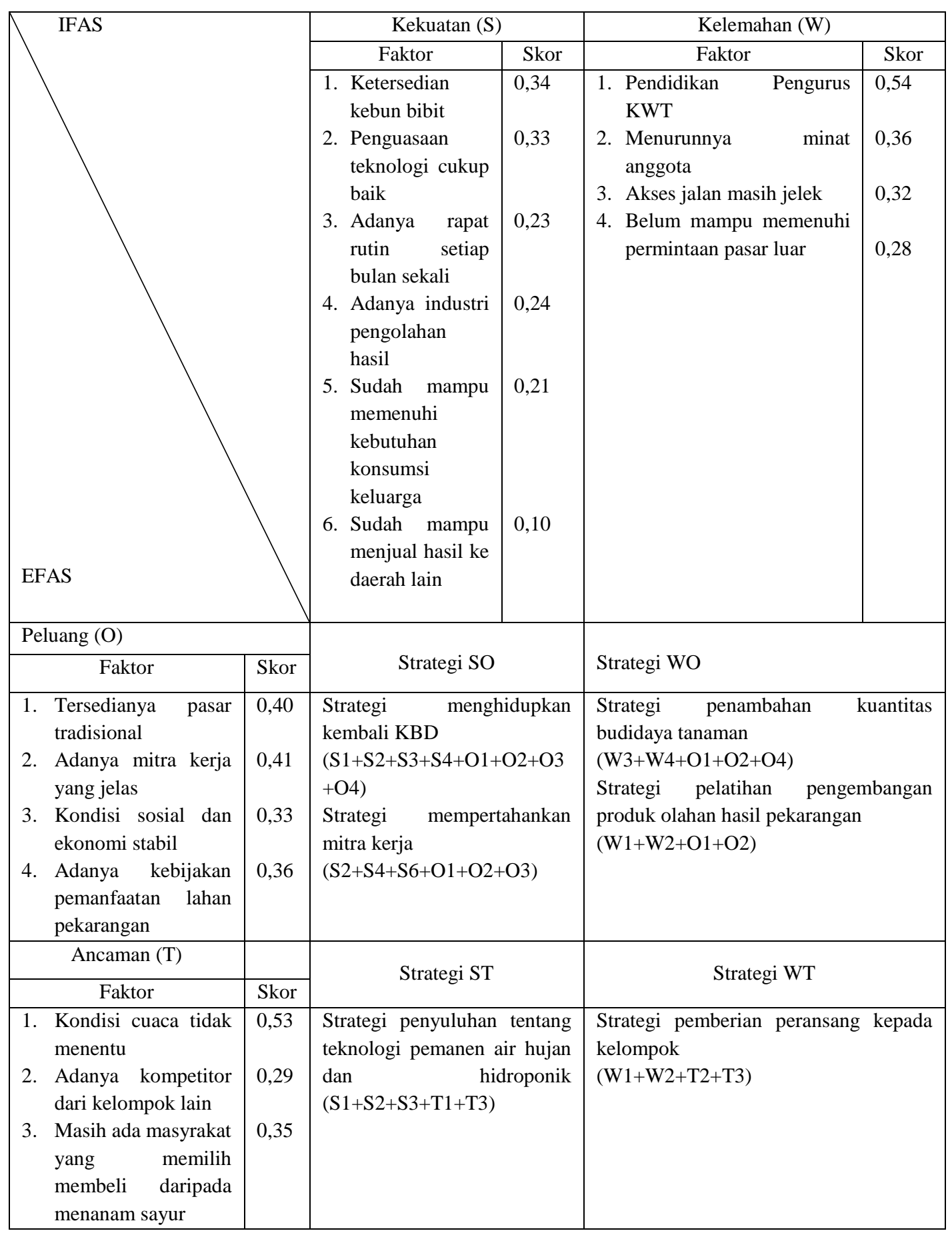

Sumber : Pengolahan data primer 2017 
Berdasarkan tabel 4 maka dapat dijabarkan alternatif strategi menggunakan analisis SWOT adalah sebagai berikut: (1) Strategi SO(strengths opportunities), strategi ini dibuat dengan memanfaatkan seluruh kekuatan untuk merebut dan memanfaatkan peluang. Strategi yang dapat dilakukan adalah menghidupkan kembali kebun bibit desa (KBD) dan strategi mempertahankan mitra kerja; (2) Strategi ST (strengths threats), strategi ini dibuat dengan menggunakan kekuatan untuk merebut dan mengatasi ancaman. Strategi ini dapat dilakukan dengan strategi penyuluhan teknologi pemanen air dan hidroponik kepada kelompok; (3) Strategi WO(weakness opportunities), strategi ini ditetapkan berdasarkan pemanfaatan peluang yang ada dengan meminimalkan kelemahan yang ada. Strategi yang dapat dilakukan yaitu penambahan kuantitas budidaya tanaman dan strategi pelatihan pengembangan produk olahan hasil pekarangan; (4) Strategi WT (weakness threats), strategi ini ditetapkan berdasarkan pada kegiatan yang bersifat defensif dan berusaha meminimalkan kelemahan yang ada serta menghindari ancaman. Strategi yang dapat diberikan dengan pemberian peransang kepada KWT.Berdasarkan hasil matriks SWOT maka prioritas utama yang harus dilakukan adalah mengembangkan program KRPL dengan menghidupkan kembali KBD dan mempertahankan mitra kerja.

\subsubsection{Diagram analisis SWOT}

Membuat diagram analisis SWOT dapat dilakukan setelah mengetahui hasil skor total dari masing- masing faktor internal dan eksternal.Berikut adalah diagram analisis SWOT pengembangan progam KRPL pada KWT Karya Harum di Desa Karang Sidemen dapat dilihat pada gambar 1.

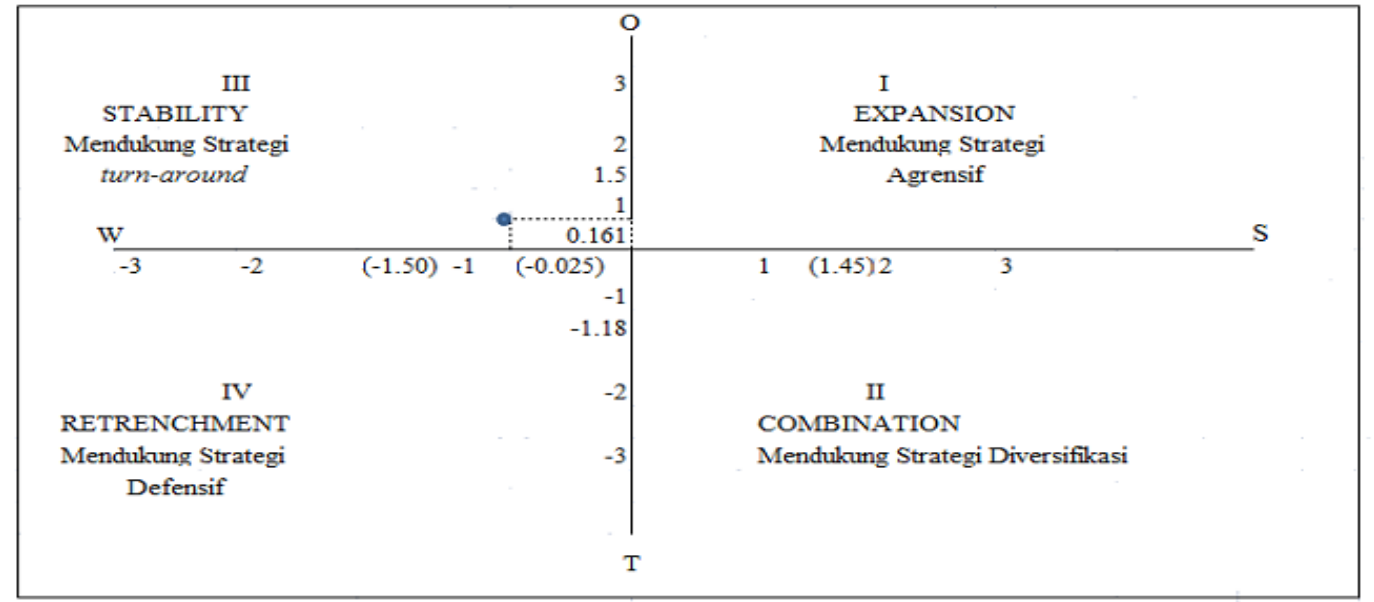

Gambar 1. Diagram SWOT Program KRPL KWT Karya Harum di Desa Karang Sidemen

Berdasarkan gambar 1 diketahui bahwa posisi pengembangan program KRPL pada KWT Karya Harum, saat ini adalah di titik III. Posisi ini menandakan sebuah organisasi yang lemah namun sangat berpeluang. Rekomendasi strategi yang diberikan adalah strategi WO dalam matriks SWOT. 


\section{Simpulan dan Saran}

\subsection{Simpulan}

Berdasarkan hasil analisis terhadap faktor lingkungan internal dan faktor lingkungan eksternal yang dapat diidentifikasi pada KWT Karya Harum di Desa Karang Sidemen dilihat dari a) Kekuatan (ketersediaan kebun bibit, pengusaan teknologi cukup baik, adanya rapat rutin setiap bulan sekali, adanya industri pengolahan hasil, sudah mampu memenuhi kebutuhan konsumsi keluarga, dan mampu menjual hasil ke daerah lain), b) Kelemahan (pendidikan pengurus KWT, menurunnya minat anggota, akses jalan masih jelek, belum mampu memenuhi permintaan pasar luar terhadap hasil), c) Peluang (adanya pasar tradisional, adanya mitra kerja yang jelas, kondisi sosial dan ekonomi stabil, adanya kebijakan pemanfaatan lahan pekarangan), dan d) Ancaman (kondisi cuaca tidak menentu, adanya kompetitor dari kelompok lain, masih banyak masyarakat yang memilih membeli daripada menanam sayur).

Berdasarkan matriks SWOT diperoleh beberapa alternatif strategi pengembangan: a) Strategi SO yaitu menghidupkan kembali kebun bibit desa (KBD) dan mempertahankan mitra kerja, b) Strategi WO yaitu strategi penambahan kuantitas budidaya tanaman dan strategi pelatihan pengembangan produk olahan hasil pekarangan, c) Strategi ST yaitu strategi penyuluhan teknologi pemanen air dan hidroponik kepada kelompok, d) Strategi WT yaitu strategi pemberian peransang. Prioritas strategi dapat dilakukan dengan menghidupkan kembali KBD dan mempertahankan produk olahan.

\subsection{Saran}

Saran yang dapat diberikan kepada KWT Karya Harum adalah memperbaiki semua kelemahan dan ancaman yang ada. Caranya dengan memperbaiki kelemahan terbesar yang ada seperti rendahnya tingkat pendidikan anggota dengan cara mengikuti pelatihan-pelatihan terkait serta mencegah berbagai macam bentuk ancaman terbesar seperti kondisi cuaca yang tidak menentu dengan menerapkan teknologi pemanen air hujan dan hidroponik. Selain itu, KWT Karya Harum perlu menghidupkan kembali KBD untuk menunjang ketersediaan bibit dengan melakukan iuran kelompok.KWT Karya Harum diharapkan agar mampu mengimplementasikan strategi alternatif yang direkomendasikan tersebut. Bagi pemerintah diharapkan agar terus menjadi pertimbangan khusus agar terus membantu KWT tersebut khususnya memberikan peransang berupa dana lanjutan sehingga kebutuhan-kebutuhan yang menjadi penunjang pelaksanaan program dapat terpenuhi dengan baik. Pemberian peransang tersebut diperlukan untuk menggerakkan minat anggota KWT untuk melaksanakan program KRPL.

\section{Ucapan Terimakasih}

Terimakasih kepada Kelompok Wanita Tani Karya Harum dan staf BPTP NTB yang telah mau memberikan informasi terkait penelitian. Seluruh pihak yang telah 
memberikan pengarahan, bimbingan dan juga dukungan dalam penyelesaian penelitian dan penulisan e-jurnal ini. Semoga penelitian ini dapat bermanfaat sebagaimana mestinya.

\section{Daftar Pustaka}

Ashari, Saptana, and Tri B P. 2012. Potensi dan Prospek Pemanfaatan Lahan Pekarangan Untuk Mendukung Ketahanan Pangan. Pusat Sosial Ekonomi dan Kebijakan Pertanian . Tersedia https://scholar.google.co.id/scholar?q=kebijakan+pemerintah+dalam+pemanfa atan+lahan+pekarangan\&btnG=\&hl=id\&as_sdt=0\%2C5. Diunduh Tanggal 17 Desember 2015.

BPTP NTB. 2012. Petunjuk Teknis Model Kawasan Rumah Pangan Lestari (MKRPL) di Nusa Tenggara Barat. Penerbit ISBN. Available online at: http://ntb.litbang.pertanian.go.id.pdf(accesed12 March 2016).

BPTP NTB. 2012. Infotek Ketahanan Pangan Rumah Tangga Berbasis IPTEK Menuju Kemandirian Pangan. Vol I No 11. Penerbit ISSN. Tersedia\{Online\}: http://ntb.litbang.pertanian.go.id/ind/bul/vol1no11.pdf. Diunduh Tanggal 8 April 2016.

BPTP NTB. 2013. Infotek Pertanian Ramah Lingkungan. Vol I No 13. Penerbit ISSN. Tersedia\{Online $\}$ : http://ntb.litbang.pertanian.go.id/ind/bul/vol1no13.pdf. Diunduh Tanggal 8 April 2016.

BPTP NTB. 2013. Infotek Peran Penyuluh NTB dalam Mendukung Percepatan Swasembada Kedelai Menuju NTB Sebagai Lumbung Kedelai Nasional. Vol II No 14. Penerbit ISSN. Tersedia\{Online\}: http://ntb.litbang.pertanian.go.id/ind/bul/vol2no14.pdf. Diunduh Tanggal 8 April 2016.

BPTP NTB. 2014. Infotek Kepemimpinan dan Kemandirian Kontak Tani Nelayan Menuju 4 Sukses Pembangunan Pertanian 2014. Vol I No 15. Penerbit ISSN. Tersedia\{Online\}: $\quad$ http://ntb.litbang.pertanian.go.id/ind/bul/vol1no15.pdf. Diunduh Tanggal 8 April 2016.

David, R, F. 2000.Manajemen Strategi. Penerbit PT Prendhallindo, Jakarta.

Rangkuti, F. 2016. Analisis SWOT Teknik Membedah Kasus Bisnis. Penerbit PT Gramedia Pustaka Utama, Jakarta.

Reksodipardjo, H.1992. Manajemen Strategik. Penerbit University Press Gajah Mada, Yogyakarta.

Siagian, S P. 2004. Manajemen Strategik. Penerbit PT Bumi Aksara, Jakarta. 